\title{
Lack of adequate care post spinal cord injury - a case report
}

\author{
Nalina Gupta ${ }^{1}$
}

Received: 14 June 2018 / Revised: 29 January 2019 / Accepted: 30 January 2019

(c) International Spinal Cord Society 2019

\begin{abstract}
Introduction Health needs of individuals with spinal cord injury (SCI) are unmet in developing countries. Quality of life of these individuals is not on par with global standards. The decline in quality of life can be attributed to lack of a specialised rehabilitation centres, lack of expertise in local hospitals and lack of access to dedicated SCI wards/centres in India. The present case report depicts many such challenges in India.

Case presentation As part of an online focus group, A 21-year-old male was identified who sustained SCI in motor vehicle. His care was inappropriate at the accident site. He was not taught basic skills such as bed mobility, transfers, and wheel-chair mobility and was not educated about long-term complications before discharged to home. Lack of training made him functionally dependent on others for his basic needs. There were few job opportunities for him in his state. He strongly emphasises the need to create an awareness regarding SCI among the general public in India.

Discussion This case report depicts many challenges faced by a person with paraplegia in India. These include mishandling at the accident site, lack of adequate care post injury and lack of follow-up post discharge. In addition, lack of knowledge of SCI among the general public and lack of education regarding SCI for the patient and his care givers post injury are reported.
\end{abstract}

\section{Introduction}

By conservative estimates, around 200,000 individuals with spinal cord injury (SCI) reside in India [1]. Every year, 10,000 new individuals are added to this population [1]. Fall from a height and road traffic accidents are the major causes of SCI in India [1]. For optimal outcomes quality, patient care must begin at the accident site and continue lifelong [2].

Unfortunately, in India, like other developing countries, the health needs of persons with SCIs are often not met and they are often denied adequate rehabilitation services [3]. In India, patients frequently initiate treatment due to comorbidities [4] that have led to a decline in community reintegration [5]. Quality of life (QoL) of persons with SCIs in India is not on par with global standards [6]. This poor QoL may be attributed to inadequate care in community

Nalina Gupta

nals235@yahoo.co.in

1 School of Physiotherapy, RK University, Rajkot, Gujarat, India, College of Physiotherapy, Sumandeep Vidyapeeth Deemed-to-beUniversity, Vadodara, Gujarat, India hospitals, and a paucity of specialised rehabilitation centres and dedicated SCI wards/centres in India [7].

Online focus group interviews were conducted to understand the expectations and experiences of patients with paraplegia in India. As a result of these interviews, many themes emerged. These themes were related to lack of knowledge regarding SCI among general public, lack of knowledge regarding care of the injured person at the accident site, difficulty with acceptance of the SCI, lack of peer-counsellors in all hospitals or lack of counselling, lack of education for patients and care-givers post injury, lack of proper assistive devices, lack of adequate training regarding basic skills of bed mobility and transfers, lack of adequate rehabilitation services and overall poor accessibility [8]. The present case report depicts a person with paraplegia in India and the challenges he described.

\section{Case presentation}

A 21-year-old male, residing in one of the villages in North India, was injured in a road traffic accident on 16 September 2014 and sustained lower extremity paralysis. The general public at the accident site tried bringing him to a sitting position but found it difficult. Once the ambulance arrived at the site, he was held from his upper and lower limbs 
without trunk support and shifted to the stretcher and then in the ambulance. He was taken to the Government hospital in a nearby city where he was found to have sustained a complete SCI with the level of lesion as T12. Surgery was performed in the same hospital. Since he described his situation without access to medical records, details of his neurological examination and management were lacking. While having an online discussion with him, he stated,

"Nobody knows about spinal cord injury in my place. I did not even know whether I should have had gone for a surgery or not. I had my accident on 16-09-2014 and was operated on 08-10-2014. My MRI was also done five days late. My surgery was done after 23 days. The doctor told me that my injury was very bad. I feel that my surgery did not go well. I should not have gone for surgery. They have cut my back for 6-7 inches. My surgery should have been at the level of injury (T12) but my surgery is of 6-7 inches. They had told me that my recovery will start after three months and nothing like that happened. They did not tell me that I will not be able to walk throughout my life."

He was discharged on 4 November 2014 from the hospital. He received minimal rehabilitation and was unable to perform basic skills such as bed mobility, transfers, activities of daily living (ADL) and wheelchair mobility on discharge. Furthermore, he was not provided education regarding his post-discharge needs and reported learning these skills from his peer. He stated,

"My initial 6-7 months were very bad. I used to be tensed as I used to shout every time to carry out my functional activity such as rolling, but now I could do most of the things by myself. I learned all these skills from my peer (person with paraplegia living near to my place). Since the time I have learned all these skills, I feel good and independent. I feel that these skills must have been taught to me earlier in the hospital."

He participated in physiotherapy for around 7-8 months at home and stated, "It is just that my back got strengthened, sitting was attained, and one to two muscles got improved after physiotherapy." Afterwards, he stopped physiotherapy as he was not improving further. There was no follow-up of his case from the acute care hospital. He denied pain but reported a pressure sore because of sitting in a wheel-chair, despite performing wheel-chair push-ups on a regular basis.

In order to be financially independent, he started taking classes at home and started working part-time in a café. He stated, "State Government should provide job facilities for persons with paraplegia."

This young man now wants to create an awareness regarding SCI as well as how to mobilise suspected victim at accident sites, as he feels that more awareness of SCI is necessary for the general public in India.

\section{Discussion}

This case report depicts many challenges which are not only faced by this young man but also by most persons with paraplegia in India regarding their post SCI care. These challenges are as follows:

\section{Lack of knowledge regarding $\mathrm{SCl}$ among general public}

Mobilisation of this individual at the accident scene was inappropriate. This could have been due to a lack of knowledge by the general public, the ambulance staff and/or the support staff of the hospital. Education regarding mobilisation of accident victims is lacking in the general public and amongst hospital personnel in India. As a result, the neurologic status of persons with SCI often declines [9]. Ways to increase awareness can include training policemen and paramedics, the primary responders, in spinal stabilisation and airway maintenance as has been implemented in Mumbai and also through social media [9]. Furthermore, initial treatment varies in specialised and non-specialised/ local centres in India, and there is often delay in admission to specialised centres [10].

\section{Lack of education post SCI}

Prior to injury, this 21-year-old male and his family had no knowledge about SCI. He was told to anticipate recovery after 3 months. He was not educated, counselled or given opportunities to ask questions while hospitalised. There is lack of education for patients' and care-givers' regarding SCI, its consequences, expected outcomes and care postdischarge in India. Patients are rarely asked for their expectations and counselled. Patients may have varying expectations based on their cultural, social and vocational backgrounds, and hence treatment goals may vary [11]. Unmet expectations of persons with SCIs may lead to dissatisfaction and a negative impact on rehabilitation outcomes [12].

Educating persons with SCIs and their families regarding injury, prognosis, and complications is very important. Without knowledge, they are more prone to develop secondary complications. Timely treatment and education of 
persons with SCIs is often unavailable in less developed countries like India due to a lack of specialised centres with a multidisciplinary approach, untrained personnel and lack of equipment [13].

Cultural settings in developing countries make it challenging to counsel individuals regarding the nature of SCI and its prognosis. Acutely post SCI, they are in denial and try to seek spiritual and faith healers [14]. Financial independence is important for any individual, including for a person with SCI. Person with SCI feel helpless and a burden to their family if they are unable to earn. Environmental barriers, societal attitude and transportation issues further restrict their ability to maintain their employment [14]. Thus, it is important for the rehabilitation professional to be sensitised and empathetic towards the patient's expectations.

Peer-counselling is another means to help newly injured persons with SCI adapt and is generally unavailable in developing countries. Hence, it has been emphasised that every professional of the rehabilitation team must be involved in educating the person with SCI [15].

\section{Lack of adequate rehabilitation care post SCI}

Based on the individuals' report, there were inadequate rehabilitation services provided. He was not taught basic skills such as bed mobility, transfers, wheel-chair mobility or managing long-term complications prior to discharge. This made him functionally dependent on others for most of his basic needs. He developed confidence once he was educated about these issues from a peer and was able to carry out his functional activities independently or with minimal assistance.

Initial treatment varies in specialised and general rehabilitation centres in India. Basic skills such as bed mobility, transfers, wheel-chair mobility, ambulation with orthotics and ADL are often not taught to persons with SCIs before discharge, especially if they are treated in non-specialised centres. Persons with SCI must learn all these skills either from peers or the internet. Maximal functional independence with the least energy expenditure is one of the most important goals of treatment for persons with SCIs. Being unable to achieve this goal could be due to a lack of knowledge, lack of specialised care, untrained personnel, lack of equipment and lack of a multidisciplinary approach [13], all of which can diminish the motivation of the patient to regain maximal independence.

Lack of adequate rehabilitation care in the hospital or at the time of discharge could also be due to the fact that there are no freely available guidelines or standards of care for persons with SCIs. Standards of care or guidelines, if freely available, could be used by the therapists in the local centres, or primary health care centres.

\section{Lack of follow-up post discharge}

There was a lack of follow-up in this case. For health maintenance and follow-up care, it is recommended that each health care teams visit persons with SCI in their community similar to the programme of Paraplegia Safari (a follow-up programme/home visit programme for persons with SCI) in India [16]. Telespinalcordinjury is also another potential means for follow ups [17], especially for patients who may lack family support or may reside in distant or rural areas with transportation and financial issues.

This case report portrays a common scenario in India. There is an urgent need to create awareness regarding SCI, handling, and care at accident sites and we believe social media may be a way to increase the general public's knowledge. Education of patients and health-care professionals is also an important way to decrease complications and improve the QoL of persons with SCI in India. Practice guidelines or standards of care regarding rehabilitation of persons with SCI and expansion of the use of tele-health would also be beneficial.

Acknowledgements We sincerely thank the participant who share his story with us and gave us his consent to publish this case report.

\section{Compliance with ethical standards}

Conflict of interest The author declares that she has no conflict of interest.

Publisher's note Springer Nature remains neutral with regard to jurisdictional claims in published maps and institutional affiliations.

\section{References}

1. Chhabra HS. Spinal cord Injury. http://www.isiconline.org.

2. Brown DJ, Judd FK, Ungar GH. Continuing care of the spinal cord injured. Paraplegia. 1987;25:296-300.

3. Axelsson C. Mapping report of physical rehabilitation services in Afghanistan, Bangladesh, Odisha (India) and Sri Lanka. Handicap International; 2014:1-144.

4. Gupta N, Solomon J, Raja K. Paraplegia: a postal survey of Morbidity trends in India. Spinal Cord. 2007;45:664-70. Epub 31 Feb 2007.

5. Sekaran P, Vijayakumari F, Hariharan R, et al. Community reintegration of spinal cord-injured patients in rural south India. Spinal Cord. 2010;48:628-32. Epub 9 Feb 2010.

6. Kandroo A, Gupta N. MPT Dissertation, College of Applied Education and Health Sciences, Meerut, India, 2012.

7. Rathore FA. Spinal Cord Injuries in the Developing World. In: JH Stone, M Blouin (eds), International Encyclopedia of Rehabilitation. 2010. Available online: http://cirrie.buffalo.edu/ encyclopedia/article.php?id=141\&language $=$ en.

8. Gupta N, Raja K. Expectations of persons with paraplegia regarding their care in India- A Qualitative study. Spinal Cord Ser Cases. 2017;3:17042. 
9. Srinivasan US. Acute spinal cord injury: managing at the site of impact and addressing reality gap. J Assoc Physicians India. 2012;60:7-9.

10. Pandey VK, Nigam V, Goyal TD, Chhabra HS. Care of posttraumatic spinal cord injury patients in India: an analysis. Indian $\mathbf{J}$ Orthop. 2007;41:295-9.

11. Harvey LA, Adams R, Chu J, Batty J, Barratt D. A comparison of patients' and physiotherapists' expectations about walking post spinal cord injury: a longitudinal cohort study. Spinal Cord. 2012;50:548-52.

12. Bowling A, Rowe G, Lambert N, Waddington M, Mahtani KR, Kenten C, et al. The measurement of patients' expectations for health care: a review and psychometric properties of a measure of patients' expectations. Health Technol Assess. 2012;16:1-532.
13. Chhabra HS, Batra S. Spinal Cord Injury and its impact on the patient, family and the society. Int J Recent Surg Med Sci. 2016;2:1-4.

14. Burns AS, O'Connell Colleen. The challenge of spinal cord injury care in the developing world. J Spinal Cord Med. 2012;35:3-8.

15. International Perspectives on Spinal Cord Injury. World Health Organisation and International Spinal Cord Society. 2013.

16. Shepherd JD, Badger-Brown KM, Wolfe DL. SCI-U: E-learning for patient education in spinal cord injury rehabilitation. J Spinal Cord Med. 2012;35:319-29.

17. Irgens I, Rekand T, Arora M, Liu N, Marshall R, BieringSorensen $\mathrm{F}$ et al. Telehealth for people with spinal cord injury: a narrative review. Spinal Cord. 2018;56:643-655. 